\title{
Mixed methods: open yourself to new opportunities
}

Laura Serrant ${ }^{a}$
DOl: http://dx.doi.org/10.1590/19831447.2015.04.59632

Traditionally, as novice researchers, learning about research methodology, students focus on mastering their understanding of and proficiency in the use of single or pure methods (usually quantitative or qualitative) as a prerequisite for effective practice. We are presented with these two paradigms as opposing approaches indeed we are encouraged to view these as polar opposites arising out of differing antecedent assumptions. Quantitative research recognises the existence of a single reality outside the control of individuals and concentrates on the gathering of 'facts', in order that 'truth claims' can be established. Qualitative researchers contend that truth and meaning do not exist in some external world, but are constructed through peoples' interactions with the world - it therefore seeks to explore how the world is understood.

However, as we become more experienced in health related research our experiences frequently make us aware of situations where utilising a single 'pure' methodology is insufficient to help us investigate some of the complexities of life and experiences. For example, a wholly qualitative approach may tell us about the concerns of a family when the father is diagnosed with cancer, but cannot fully inform us of the best treatment and the optimal dosage to enable him to continue to participate in family life. Conversely quantitative measures can detect risks of illness in deprived neighbourhoods but, if utilized in isolation, fails to give us insight into the experiences of families living there and how best to support them.

Mixed methods offer researchers opportunities to explore issues from multiple angles - quantitative and qualitative approaches provide different "pictures" enabling a fuller understanding of issues. They are invaluable in situations such as those mentioned above, where it is important to both understand an issue as well as determine how to apply solutions in everyday life. Mixed methods are underpinned by Pragmatism. Pragmatism seeks to apply the most appropriate methods to answer a question (what works best) dependent on the actions required, situations in which the research takes place and likely consequences to be considered rather than antecedent (pre-existing) conditions. Researchers are thus enabled to use all approaches available to understand the problem. In this way, mixed methods are "intuitive" - mirroring "real life" allowing us the flexibility to combine methodologies as required.

Life in the $21^{\text {st }}$ century is complex. Advances in science and changes in lifestyle mean that we often face challenges to our health and wellbeing that our parents and grandparents could never have imagined. Seeking answers is further complicated by researchers' need to engage with situations incorporating diverse and often seemingly competing factors. Mixed methods allow us to develop our research skills and adapt our research to respond to the questions asked. This is particularly pertinent when research seeks not only to discover'cause' or identify'experiences' but also to find possible solutions or suggest practical ways forward.

Combining the 'Science' and 'Art' of research methods opens up a breadth of researcher opportunities - I invite you to think differently about your research; be brave, consider mixing your methods.

University of Wolverhampton, Faculty of Education, Health and Wellbeing. Wolverhampton, United Kingdom. 


\section{REFERENCES}

For further information about Mixed methods see:

Creswell JW. Research design: qualitative, quantitative, and mixed methods approaches. $4^{\text {th }}$ ed. Los Angeles: Sage Publications; 2013.

Creswell JW, Klassen AC. Plano Clark VL, Smith KC. Best practices for mixed methods research in the health sciences. Bethesda (MD): National Institutes of Health, Office of Behavioral and Social Sciences Research, 2011.

Teddlie C, Tashakkori A. Mixed methods research: contemporary issuers in an emerging field. In: Denzin N, Lincoln Y, editors. The Sage handbook of qualitative research. Los Angeles: Sage; 2011. p. 285-300.

Torrance H. Triangulation, respondent validation, and democratic participation in mixed methods research. J Mix Methods Res. 2012;6(2):111-23. 